\title{
Path analysis of influencing factors of completeness evaluation in Sanyizhai Irrigation Area
}

\author{
FENG Feng ${ }^{1,2, *}$, ZHAO Ting ${ }^{1,2}$, JIANG Nan $^{1,2}$, ZHANG Fang $^{1,2}$, WANG Mengzhen ${ }^{3}$, FENG Yuehua ${ }^{4}$ \\ ${ }^{1}$ Yellow River Conservancy Technical Institute, Kaifeng 475004 China \\ ${ }^{2}$ Henan Engineering Technology Center for Water Resources Conservation and Utilization in the Middle and Lower Reaches of Yellow \\ River, Kaifeng 475004 China \\ ${ }^{3}$ Eastern Henan Water Conservancy Administration Bureau, Sanyizhai Branch Office, Kaifeng, 475300, China \\ ${ }^{4}$ Eastern Henan Water Conservancy Administration Bureau, Kaifeng 475002, China
}

\begin{abstract}
Completeness are comprehensive evaluation of the development status of irrigated areas. The study of their main influencing factors can provide strong data support for the high-quality development of irrigated areas. The paper choose the data during 2005 to 2014 of Sanyizhai Irrigation Area as analysis samples, clear different key factors affecting the evaluation target, in which six factors equal, according to different evaluation subjects and goals, the same impact factor of direct effect and indirect effect, decision coefficient and significant contribution to total $R^{2}$. For the comprehensive completeness of Yellow River Sanyizhai Irrigation Area, the channel length is the most important influencing factor. The actual irrigation area, mechanism setting and channel lining rate have a significant influence on the comprehensive completeness evaluation of Yellow River Sanyizhai Irrigation Area, while the direct effect of the actual water amount is the least. Compared with the simple correlation coefficient and regression analysis method, the path analysis method can accurately calculate the direct and indirect effects of the independent variables on the dependent variables, which has the advantages of intuitive, scientific and reasonable. According to the analysis results, it can make clear the direction of efforts for the upgrading and transformation of the irrigation area and the development of high quality.
\end{abstract}

\section{Introduction}

In the major national strategy of ecological protection and high-quality development of the Yellow River Basin, it is clearly pointed out that water should be determined by water, water should be measured, and water resources should be conserved and utilized intensively [1]. Yellow River irrigation is mainly agricultural water. For the important precondition of economical and intensive utilization of water resources is the crop water requirements in irrigation area and the main influence factors analysis, on the basis of the ability in the implementation of precision irrigation area with water irrigation, and wisdom to achieve really save the Yellow River water resources, improve the efficiency of water use of Yellow River water [2]. Cui Dangqun proposed a matrix algorithm for path analysis, and took sweet potato as a case to conduct path analysis and significance test [3]. Cai Bingjia judged the sensitivity of the water shortage diagnostic index of winter wheat based on the principle of path analysis, and determined the main factors that should be paid attention to in irrigation decision-making index [4]. Wei Qingshun confirmed the primary and secondary factors affecting the performance of submersible pumps through path analysis of the geometric parameters of the diverter [5]. At present, for the application of path analysis, there are many research results from different cases and perspectives, but few results related to the comprehensive completeness of Sanyizhai Irrigation Area. In this paper, based on previous acquired comprehensive complete degree evaluation of research results, by sizing analysis to determine the degree of water use efficiency and the comprehensive complete direct effect, indirect utility maximum impact factors, determine the relationship between these factors, to economical and intensive utilization of water resources of Yellow River Sanyizhai Irrigation Area and high quality development provides a solid basis of data base and support.

\section{Study area and analysis method}

\subsection{Regional general situation Path analysis method}

The total land area of Sanyizhai Irrigation Area in Henan Province is $4344.2 \mathrm{~km}^{2}$, and the total cultivated land area is $270,000 \mathrm{hm}^{2}$ [6]. The area of each region after partitioning is counted, as shown in Table 1 and Figure 1.

\footnotetext{
* Corresponding author: fengfeng_624@163.com
} 
Table 1. Planned irrigated area of each district (Unit: 10,000)

\begin{tabular}{|c|c|c|c|c|}
\hline No. & District & $\begin{array}{c}\text { Fully } \\
\text { irrigated } \\
\text { area }\end{array}$ & $\begin{array}{c}\text { Insufficien } \\
\text { tly } \\
\text { irrigated } \\
\text { area }\end{array}$ & $\begin{array}{c}\text { The } \\
\text { partitio } \\
\text { n area }\end{array}$ \\
\hline 1 & $\begin{array}{c}\text { Lankao } \\
\text { South } \\
\text { District }\end{array}$ & 35.26 & - & 35.26 \\
\hline 2 & $\begin{array}{c}\text { Lankao } \\
\text { North } \\
\text { District }\end{array}$ & 15.00 & 28.70 & 43.70 \\
\hline 3 & $\begin{array}{c}\text { Kaifeng } \\
\text { County } \\
\text { District }\end{array}$ & 6.93 & - & 6.93 \\
\hline 4 & $\begin{array}{c}\text { Qi County } \\
\text { District }\end{array}$ & 25.61 & - & 25.61 \\
\hline 5 & $\begin{array}{c}\text { Minquan } \\
\text { South } \\
\text { District }\end{array}$ & - & 8.00 & 8.00 \\
\hline 6 & $\begin{array}{c}\text { Minquan } \\
\text { North } \\
\text { District }\end{array}$ & 40.51 & 2.00 & 42.51 \\
\hline 7 & $\begin{array}{c}\text { Sui County } \\
\text { District }\end{array}$ & - & 27.01 & 27.01 \\
\hline 8 & $\begin{array}{c}\text { Ningling } \\
\text { District }\end{array}$ & 3.00 & 39.68 & 42.68 \\
\hline 9 & $\begin{array}{c}\text { Shangqiu } \\
\text { City District }\end{array}$ & 8.00 & 42.60 & 50.00 \\
\hline 10 & $\begin{array}{c}\text { Yucheng } \\
\text { District }\end{array}$ & - & 43.70 & 43.70 \\
\hline al & $\begin{array}{c}\text { - } \\
\text { al }\end{array}$ & 134.31 & 191.69 & 326.00 \\
\hline
\end{tabular}

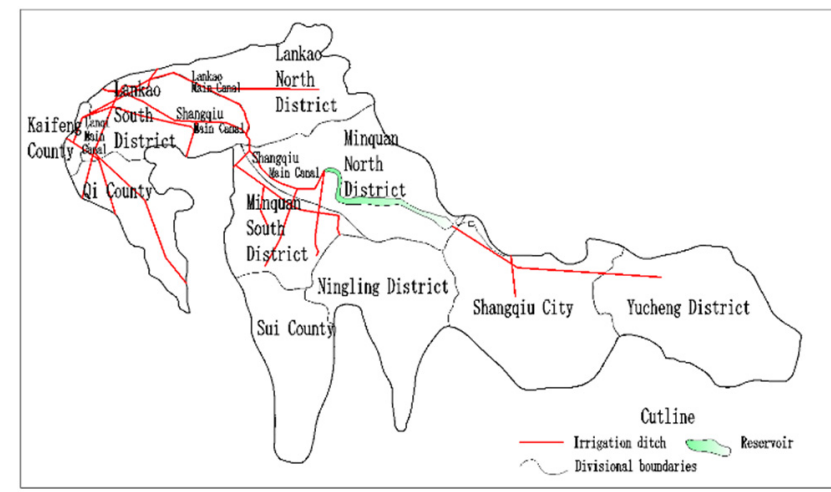

Figure 1. Zoning map of Sanyizhai Irrigation Area in Henan Province

\subsection{Path analysis method}

Path coefficient is a statistic representing the influence relationship between related variables. It is a variable standardized partial regression coefficient without unit. It is the correlation coefficient with direction between independent variable and dependent variable. Path coefficient is the partial regression coefficient after the standardization of variables, and its mathematical model is the multiple linear regression model after the standardization of partial regression coefficient [7]. In order to make the results accurate and easy to understand, the relevant matrix algorithm [5] and mathematical model [6] are used in this paper to carry out the related calculation of path analysis. For an interrelated system, if there are $\mathrm{n}$ independent variables $x_{i}(i=1,2 \ldots n)$ and one dependent variable $y$, and the regression equation is

$$
y=b_{0}+b_{1} x_{1}+b_{2} x_{2}+\cdots+b_{n} x_{n}
$$

According to the simple correlation coefficient $r_{x i x j}(i$, $j \leqslant n$ ) between the respective variables and the simple correlation coefficient $r_{x i y}(i \leqslant n)$ between the respective variables and the dependent variable, through mathematical transformation of Equation (1), the normal matrix equation is established as

$$
\left[\begin{array}{cccc}
1 & r_{x_{1} x_{2}} & \cdots & r_{x_{1} x_{n}} \\
r_{x_{2} x_{1}} & 1 & \cdots & r_{x_{2} x_{n}} \\
\vdots & \cdots & \cdots & \vdots \\
r_{x_{n} x_{1}} & r_{x_{n} x_{2}} & \cdots & 1
\end{array}\right]\left[\begin{array}{c}
p_{y x_{1}} \\
p_{y x_{2}} \\
\vdots \\
p_{y x_{n}}
\end{array}\right]=\left[\begin{array}{c}
r_{x_{1} y} \\
r_{x_{2} y} \\
\vdots \\
r_{x_{n} y}
\end{array}\right]
$$

By solving the matrix equation (2), the path coefficient $P_{y x i}$ can be obtained, which represents the direct path coefficient of the independent variable $x_{i}$ on the dependent variable $y$, and is the direct action effect of $x_{i}$ on $y \cdot r_{x i x} p_{y x j}$ represents the indirect path coefficient of independent variable $x_{i}$ on dependent variable y through $x_{j}$, and is the indirect effect of $x_{i}$ on dependent variable $y$ through $x_{j}$. The path coefficient $p_{y e}$ of the remaining term is expressed as

$p_{y e}=\sqrt{1-\left(r_{x_{1} y} p_{y x_{1}}+r_{x_{2} y} p_{y x_{2}}+\cdots+r_{x_{n} y} p_{y x_{n}}\right)}$

If the path coefficient $p_{y e}$ of the remaining items is small, it indicates that the main factors affecting the dependent variables have been found out.If the value of $P_{y e}$ is large, it indicates that the test error is large or more important independent variables are not taken into account [8].

$$
\begin{aligned}
& d_{y x_{i}}=b_{x_{i}}{ }^{2} \frac{\sigma_{x_{i}}{ }^{2}}{\sigma_{y_{i}}{ }^{2}}=p_{y x_{i}}{ }^{2}(i=1,2, \cdots, m) \\
& d_{y x_{i} x_{j}}=2 p_{y x_{i}} p_{y x_{j}} r_{x_{i} x_{j}}(i, j=1,2, \cdots, m, i<j) \\
& d_{y e}=1-\left(\sum_{i=1}^{m} d_{y x_{i}}+\sum_{i<j}^{m} d_{y x_{i} x_{j}}\right)=1-R^{2}
\end{aligned}
$$

The total contribution of $x_{i}$ to the estimation of reliability $R^{2}$ of regression equation is as follows:

$$
p_{y x_{i}} \cdot r_{x_{i} y}(i=1,2, \cdots, n)
$$

\section{Path analysis of completeness of Sanyizhai Irrigation Area}

\subsection{Selection of impact factors}

In order to clarify the key influencing factors of the completeness evaluation results of the Yellow River Irrigation Area the evaluation indexes of Sanyizhai Irrigation Area from 2005 to 2014 were selected to carry out path analysis and calculation. According to the 
previous research results [9], the comprehensive completeness evaluation of Sanyizhai Irrigation Area is based on 9 indicators, and the fuzzy variable evaluation of relative difference degree function is carried out. Size selection analysis for years as the calculating unit 10 samples from 2005 to 2014, excluding the two qualitative indicators, select the following seven factors affecting the sizing analysis: facilities intact rate, the actual diverted, channel length, channel lining rate, actual irrigation area, institutions, water saving engineering investment, using three different weight vector of comprehensive complete degree average for the dependent variable.The analysis indexes used include the correlation coefficient $r_{i j}$, path coefficient $P_{y x i}$, determination coefficient $d_{y x i}$ and the total contribution to the reliability of regression equation $R^{2}$, etc.

\subsection{Path analysis of comprehensive completeness}

For three righteousness village cooperatives, the based on the analysis of complete degree of sizing, selection of seven factors: facilities pipe $\left(X_{1}\right)$, the actual $\left(X_{3}\right)$ been obtained $\left(X_{2}\right)$, channel length, channel lining rate $\left(X_{4}\right)$, the actual irrigation area $\left(X_{5}\right)$, institutions $\left(X_{6}\right)$, water saving engineering investment $\left(X_{7}\right)$, the dependent variable for processing after the evaluation of the level characteristic value $Y_{l}$, according to the size coefficient and correlation coefficient (as shown in Table 2), get Sanyizhai Irrigation Area water use efficiency and seven impact factor and the error term of the size chart, as shown in Figure 2.

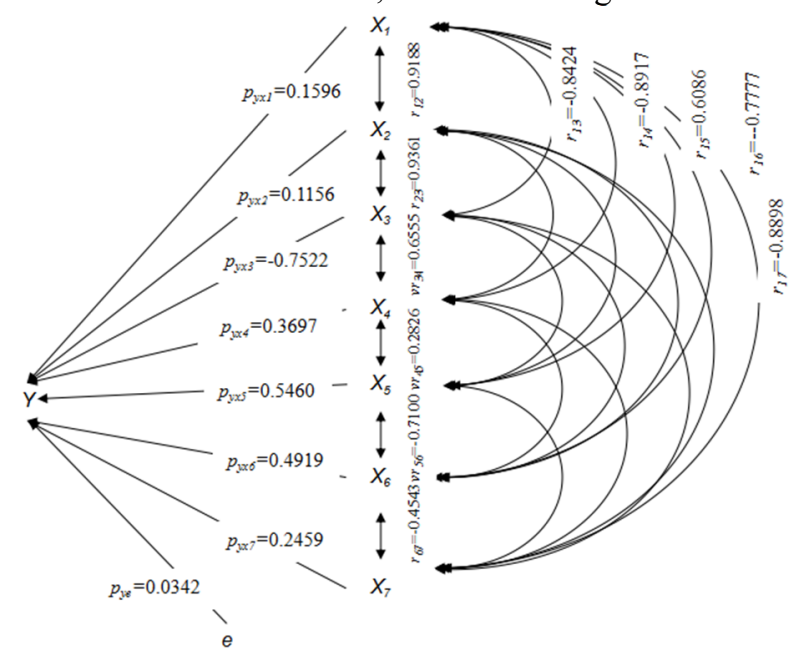

Figure 2. Path relation diagram of 7 influencing factors on comprehensive completeness of Sanyizhai Irrigation Area

Table 2. Correlation coefficient $r$ between comprehensive completeness and influencing factors in Sanyizhai Irrigation Area

\begin{tabular}{cllllllll}
\hline Factor & $\boldsymbol{X}_{\boldsymbol{1}}$ & $\boldsymbol{X}_{\boldsymbol{2}}$ & $\boldsymbol{X}_{\boldsymbol{3}}$ & $\boldsymbol{X}_{\boldsymbol{4}}$ & $\boldsymbol{X}_{\boldsymbol{5}}$ & $\boldsymbol{X}_{\boldsymbol{6}}$ & $\boldsymbol{X}_{\boldsymbol{7}}$ & $\boldsymbol{Y}_{\boldsymbol{1}}$ \\
\hline$X_{1}$ & 1.0000 & 0.9188 & 0.8424 & 0.8917 & 0.6086 & 0.7777 & 0.8898 & 0.9124 \\
$X_{2}$ & 0.9188 & 1.0000 & 0.9361 & 0.8418 & 0.5344 & 0.8889 & 0.6657 & 0.8164 \\
$X_{3}$ & 0.8424 & 0.9361 & 1.0000 & 0.6555 & 0.6914 & 0.9916 & 0.5332 & 0.8471 \\
$X_{4}$ & 0.8917 & 0.8418 & 0.6555 & 1.0000 & 0.2826 & 0.5534 & 0.7909 & 0.6763 \\
$X_{5}$ & 0.6086 & 0.5344 & 0.6914 & 0.2826 & 1.0000 & 0.7100 & 0.4925 & 0.8762 \\
$X_{6}$ & 0.7777 & 0.8889 & 0.9916 & 0.5534 & 0.7100 & 1.0000 & 0.4543 & 0.8178 \\
$X_{7}$ & 0.8898 & 0.6657 & 0.5332 & 0.7909 & 0.4925 & 0.4543 & 1.0000 & 0.8051 \\
\hline
\end{tabular}

After the equation (2) is converted into a normal matrix equation, the calculation method is the same as above. The direct and indirect effects of each influence factor on the comprehensive completeness of Sanyizhai Irrigation Area are calculated. The results are shown in Table 3. Equations (4) - (7) were used to calculate the determination coefficients among all the influencing factors, and the first 6 with the largest absolute value and the determination coefficients of the error term were ranked. The top 7 impact factors of the total contribution of each independent variable to $R^{2}$ were ranked as shown in Table 4.

Table 3. The influence factors direct and indirect effects on the comprehensive completeness of Sanyizhai Irrigation Area

\begin{tabular}{|c|c|c|c|c|c|c|c|c|c|c|c|}
\hline \multirow[t]{2}{*}{ Independent variable } & \multirow{2}{*}{$\begin{array}{c}\text { Correlation } \\
\text { coefficient } \\
r_{y x i}\end{array}$} & \multirow{2}{*}{$\begin{array}{c}\begin{array}{c}\text { Direct } \\
\text { effect }\end{array} \\
P_{y x i}\end{array}$} & \multicolumn{3}{|c|}{ Indirect effect } & \multicolumn{5}{|c|}{ (By the following independent variables) } & \multirow[b]{2}{*}{$X_{8}$} \\
\hline & & & Total & $X_{1}$ & $X_{2}$ & $X_{3}$ & $X_{4}$ & $X_{5}$ & $X_{6}$ & $X_{7}$ & \\
\hline$X_{1}$ & 0.9124 & 0.1596 & 0.7359 & & 0.1062 & -0.6336 & 0.3296 & 0.3323 & 0.3825 & 0.2188 & 0.7359 \\
\hline$X_{2}$ & 0.8164 & 0.1156 & 0.6465 & 0.1466 & & -0.7041 & 0.3112 & 0.2918 & 0.4373 & 0.1637 & 0.6465 \\
\hline$X_{3}$ & 0.8471 & -0.7522 & 1.4813 & 0.1344 & 0.1082 & & 0.2423 & 0.3775 & 0.4878 & 0.1311 & 1.4813 \\
\hline$X_{4}$ & 0.6763 & 0.3697 & 0.3675 & 0.1423 & 0.0973 & -0.4931 & & 0.1543 & 0.2722 & 0.1945 & 0.3675 \\
\hline$X_{5}$ & 0.8762 & 0.5460 & 0.2137 & 0.0971 & 0.0618 & -0.5200 & 0.1045 & & 0.3492 & 0.1211 & 0.2137 \\
\hline$X_{6}$ & 0.8178 & 0.4919 & 0.1850 & 0.1241 & 0.1028 & -0.7459 & 0.2046 & 0.3877 & & 0.1117 & 0.1850 \\
\hline$X_{7}$ & 0.8051 & 0.2459 & 0.6027 & 0.1420 & 0.0770 & -0.4010 & 0.2924 & 0.2689 & 0.2235 & & 0.6027 \\
\hline
\end{tabular}


Table4. Determining coefficient of influence factors on comprehensive completeness and ranking of total contribution to $R^{2}$ of Sanyizhai Irrigation Area

\begin{tabular}{ccccc}
\hline Rank & Factor & $\begin{array}{c}\text { Determination } \\
\text { coefficient }\end{array}$ & $\begin{array}{c}\text { Independent } \\
\text { variable }\end{array}$ & $\begin{array}{c}\text { Total contribution } \\
\text { to } \boldsymbol{R}_{2}\end{array}$ \\
\hline 1 & $d_{y \times 3 x 6}$ & -0.7338 & $X_{3}$ & -0.6371 \\
2 & $d_{y \times 3 x 5}$ & -0.5678 & $X_{5}$ & 0.4787 \\
3 & $d_{y x 3}$ & 0.5658 & $X_{6}$ & 0.4023 \\
4 & $d_{y \times 5 x 6}$ & 0.3814 & $X_{4}$ & 0.2500 \\
5 & $d_{y x 3 x 4}$ & -0.3646 & $X_{7}$ & 0.1980 \\
6 & $d_{y x 5}$ & 0.2981 & $X_{1}$ & 0.1456 \\
Error term & $d_{y e}$ & 0.0012 & $X_{2}$ & 0.0944 \\
\hline
\end{tabular}

\section{Conclusion}

According to Table 3 in Sanyizhai Irrigation Area based on the analysis of complete degree evaluation of the size as a result, each influence factor of the path coefficient $P_{y x i}$ known as the via direct effect on the comprehensive complete results, the effects of absolute value of the largest first four factors: the length of the channel $\left(X_{3}\right)$, the actual irrigation area $\left(X_{5}\right)$, institutions $\left(X_{6}\right)$, the rate of channel lining $\left(X_{4}\right)$, minimal direct effect actually been obtained $\left(X_{2}\right)$. The significance test of the coefficient of determination showed that $d_{y x 3 x 6}, d_{y x 3 \times 5}$ and $d_{y x 3}$ were all extremely significant $(\alpha<0.01)$, and it can be approximately considered that the coefficient of determination with absolute value greater than $d_{y x 3}$ (0.5658) is significant, and that with absolute value less than $d_{y x 3}$ is not significant. According to Table 4 each influence factor on the cooperatives, the comprehensive complete decision coefficient, the length of the channel $\left(X_{3}\right)$, institutions $\left(X_{6}\right)$, joint action of $Y_{1}$ relative decision coefficient is 0.7338 , the first bit of each factor and the $X_{3}$ to $R^{2}$ total contribution is 0.6371 , is the absolute value, the biggest show that channel length $\left(X_{3}\right)$ is the most important factors influencing cooperatives. The comprehensive complete impact factor. The interaction of channel length $\left(X_{3}\right)$, actual irrigation area $\left(X_{5}\right)$, mechanism setting $\left(X_{6}\right)$ and channel lining rate $\left(X_{4}\right)$ occupied the top five positions of the determination coefficient and also the top four positions of the total contribution to $R^{2}$, indicating that these four factors played a significant role in the comprehensive completeness evaluation of the Yellow River diversion irrigation area under the combined action of these four factors. The path coefficient of the error term on the comprehensive completeness $Y_{l}$ is 0.0342 , and the relative determination coefficient is 0.0012 , both of which are the minimum, indicating that all the factors that have a greater impact on the comprehensive completeness of the irrigated area have been taken into account, the evaluation error is small, and the calculation result of the completeness is more accurate.

In order to clarify the key influencing factors of the completeness evaluation results of the Yellow River Irrigation District, the same evaluation indexes were selected for path analysis and calculation in the Sanyizhai Yellow River Irrigation District during the 10 years from 2005 to 2014. According to different evaluation subjects and goals, the same impact factor of direct effect and indirect effect, decision coefficient and significant contribution to total $R^{2}$.

As for the comprehensive completeness of Yellow River Sanyizhai Irrigation Area, the channel length is the most important influencing factor. The actual irrigation area, institutional setting and channel lining rate have a significant effect on the comprehensive completeness evaluation of Sanyizhai Irrigation Area, while the direct effect of the actual water diversion is the least.Therefore, in order to improve the comprehensive completeness score of Sanyizhai Irrigation Area, it is necessary to extend the length of the channel, expand the irrigation area, improve the management level and perfect the institutional setting.

Through the analysis, the direct and indirect effects of error terms on water use efficiency and comprehensive completeness evaluation are the minimum, indicating that for water use efficiency and comprehensive completeness evaluation of irrigation district, the factors with greater influence are all taken into account in the evaluation, so the evaluation error is small and the calculation results are more accurate. Compared with the simple correlation coefficient and regression analysis method, the path analysis method can accurately calculate the direct and indirect effects of the influence of independent variables on dependent variables, and has the advantages of intuition, science and rationality. According to the analysis results, the direction of focus can be defined for the upgrading and supporting transformation and high-quality development of Sanyizhai Irrigation Area.

\section{Acknowledgement}

This paper is supported by the following projects: National Natural Science Foundation of China (No. 51809110); Key Scientific Research Project of Higher Education of Henan Province(No.18A570006); Key Project of Water Resources Science and Technology of Henan Province in 2019(No.GG201938); Kaifeng Yellow River Basin Ecological Protection and High-quality Development Innovation Special Program in 2020( No.2019012). This paper is the stage research result of the above research projects.

\section{References}

1. Xinhua: At this symposium, Xi Jinping put forward a major national strategy $[\mathrm{EB} / \mathrm{OL}]$. http://www.xinhuanet.com/politics/xxjxs/2019- 
09/19/c_1125016382.htm.

2. Central Committee of the Communist Party of China and State Council.About the implementation of the development of new ideas to speed up agricultural modernization to realize the goal of the all-round well-off society several opinions [EB/OL]. [2018-1205] [2020-10-21] HTTP:

http://www.xinshishe.com/html/news_2016/12/3133 256295491281.html.

3. CUI Dangqun. Matrix Algorithm for Path Analysis [J]. Acta Biomathematica Sinica,1994,9(1):71-76.

4. CAI Jiabing, LIU Yu, XU Di, et al . Sensitivity analysis on water deficit indicator of winter wheat based on path analysis theory[J]. Journal of Hydraulic Engineering, 2008, 39(1):83-90.

5. WEI Qingshun, SUN Xihuan, LIU Zailun, et al.Path Analysis of Influence of Geometric Parameters of Diversion on Performance of Submersible Pump [J]. Journal of Drainage and Irrigation Machinery Engineering,2014,32(3):202-207.

6. WU Bin, WANG Aizhen, ZHAO Yi, et al.Planning Report on the Renewal of Supporting Facilities and Water Saving Transformation in Sanyizhai Yellow River Sanyizhai Irrigation Area in Henan Province [R]. Kaifeng: Kaifeng Water Conservancy Building Exploration and Design Institute, 2008.68-72.

7. FENG Feng, Jia Hongtao, Meng Yuqing.Evaluation of effective utilization of irrigation water based on flow tracking method [J]. Yellow River, 2017, 39(5):140-143.

8. FENG Feng, SUN Ying, FENG Yuehua, et al. Evaluation of completeness degree of Yellow River Sanyizhai Irrigation Area based on flow direction tracking and difference degree [J]. Yellow River, 2019, 41(11):159-164.

9. FENG Feng, Ni Guangheng, Meng Yuqing.Evaluation of water use efficiency in Yellow River Sanyizhai Irrigation Area based on water flow tracking and multiple weights [J]. Transactions of the Chinese Society of Agricultural Engineering, 2017, 33(5): 145-153. 